\title{
Features of designing hydraulic excavator in APM WinMachine
}

\author{
Viktor Shestakov ${ }^{1, *}$, Pavel Babenkov ${ }^{1}$, and Sergey Horoshavin ${ }^{1,2}$ \\ ${ }^{1}$ Ural State Mining University, 30, Kuibyshev St., Yekaterinburg, 620144, Russia \\ ${ }^{2}$ Ural Federal University named after the first President of Russia BN. Yeltsin, 19, Mira St., \\ Yekaterinburg, 620002, Russia
}

\begin{abstract}
The urgency of the work is due to the need for design departments involved in the design of hydraulic excavators in techniques. Allowing to reduce the weight of excavators while providing at the same time sufficient reliability. The purpose of the work: development of a technique for application in the design of excavators of calculation modules based on the use of finite elements. Research methodology: modeling of working equipment. For a hydraulic excavator with a "direct" shovel working equipment, a mathematical model for calculating effort, an algorithm and a program in an algorithmic language have been developed, which allow to determine the working area of the excavator, possible digging forces, and efforts in the elements of the working equipment. To calculate stresses in the design of the working equipment, two modeling options are proposed: the models for the Strucrure 3D computational module are compiled separately for the bucket of the handle and the boom, the interaction of the models is carried out by efforts that are determined by the specified digging forces; a complete model of all the working equipment for the calculation module is compiled, without the need to calculate the loads between the elements, the calculation is carried out directly by the digging force. For the first variant formulas of calculation of efforts in elements of the working equipment are resulted. For the second variant, it is suggested to use a plate-rod model, and recommendations are given for the implementation of the relationships between the boom, the handle and the bucket. The results of stress calculations for the working equipment are presented.
\end{abstract}

\section{Introduction}

Hydraulic excavators in comparison with rope excavators with equal capacity of buckets have a smaller in $1.8 \ldots 2.2$ times mass, develop large digging efforts $[1,2, \ldots, 1,3]$. ]. A great influence on the productivity and cost of the excavator is influenced by working equipment [5-7]. Reducing the weight of equipment significantly reduces the weight of the excavator, the moment of inertia of its turning part. The reserve for reducing the weight of the elements of the working equipment (booms, hilt, bucket, etc.) in the selection of

\footnotetext{
*Corresponding author: shestakov.v.s@mail.ru
} 
optimum cross-sections of these elements, in the rational arrangement of hydraulic cylinders [8].

\section{Purpose and objectives of work}

At the present time, a technique has been developed in which the first variant of the construction of the working equipment is worked out, taking parameters similar to existing models $[2,3]$, for it, according to the required digging forces, forces in hinges, brackets, boom supports are determined, and then calculations are performed stresses to check strength. For the elements that do not provide the condition of strength, constructive changes are made, and stress calculation is repeated.

A large number of publications have been devoted to the development of methods for calculating the forces for hydraulic excavators [6-15]. Calculation of efforts in these techniques is carried out with the given efforts on the rods of hydraulic cylinders turning the bucket, hilt and boom.

The disadvantage of this approach is the complexity of the selection of the parameters of power cylinders, since it is impossible to calculate the force on the rods of a separate hydraulic cylinder for the required digging force.

The purpose of the performed studies was the development of a technique for calculating the parameters of the working equipment of a hydraulic excavator, which provides the calculation of the required forces on the rods of hydraulic cylinders and stresses.

\section{Solving research problems}

To calculate the stresses and power parameters in the elements of the working equipment, it is proposed to use the calculation module Strucrure 3D of the APM WinMacine system, including the finite element method.

The technique of designing the working equipment of the excavator is made in two versions:

1. Models for the Strucrure 3D computational module are compiled separately for the bucket and boom, the interaction of models is carried out by forces in the connecting nodes, which in turn are determined by the specified digging forces [10].

2. A complete model of all working equipment for the calculation module is compiled, without the need to calculate the loads between the elements, the calculation is carried out directly by the digging force..

The first option corresponds to the established practice of calculating the stress-strain state of excavator-like complex systems similar to the working equipment - the systems are divided into subsystems and modeled separately. The connections between the subsystems are performed by specifying the forces and supports.

The difficulty in calculating the values of effort between the bucket, handle and boom is the presence of limitations on the part of the power elements - hydraulic cylinders. The maximum force on the teeth of the bucket is formed not by a single mechanism, as on rope excavators, but by any of the listed hydraulic cylinders [4-13]. The second peculiarity complicating the calculation formulas is the variability of the arms of the action of forces on the part of the force elements in the process of digging, and also the dependence on the position of the bucket within the working zone (Figure 1). 


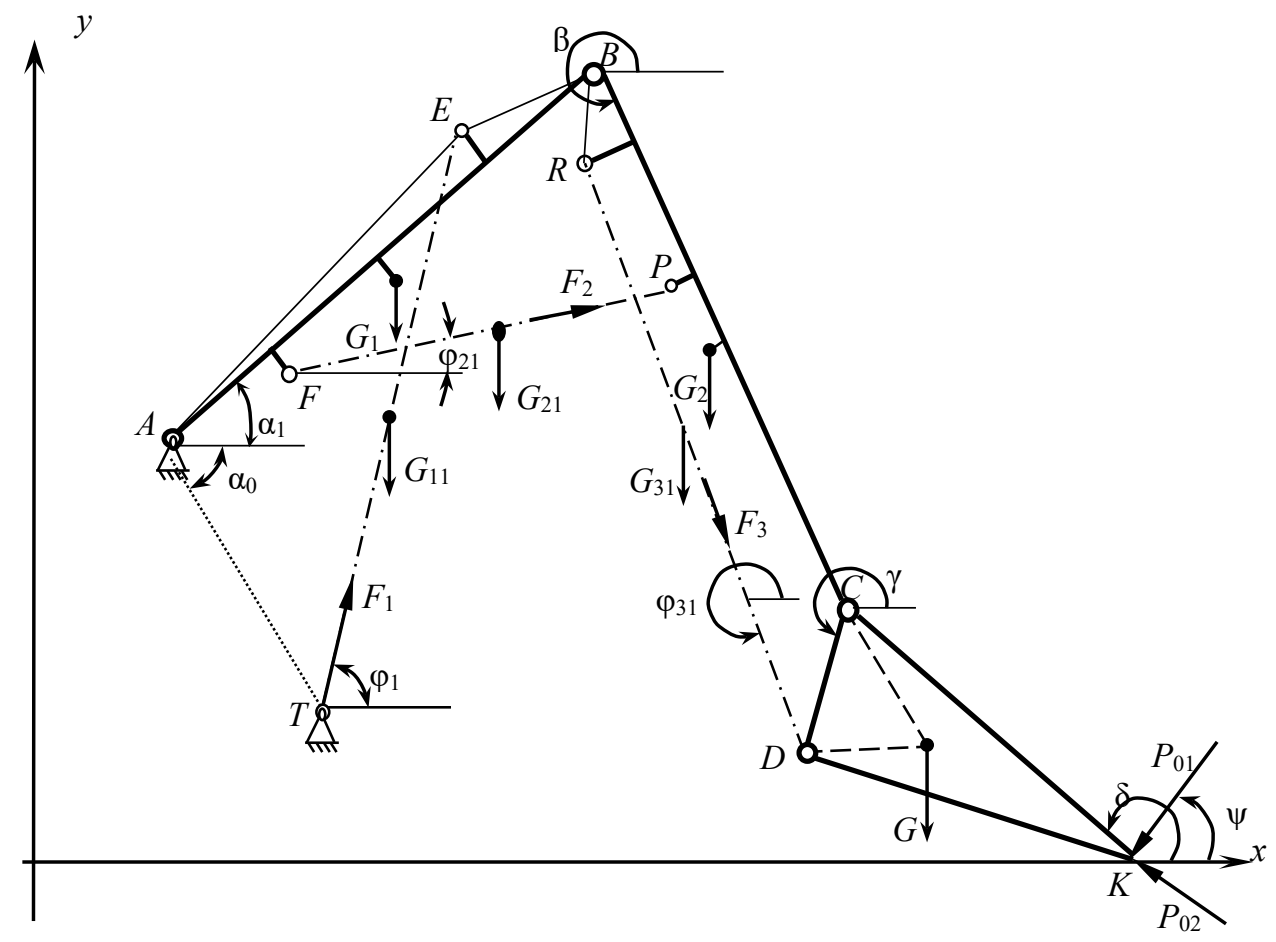

Fig. 1. Scheme for calculating the parameters of the working equipment:

$A, T, E, F, P, R, B, C, D$ - hinges; $K$ - is the top of the bucket tooth; $K C D$ - bucket profile diagram; $C B$ - handle; $A B$ - boom; $T E, F P, R D$ - hydraulic cylinders for turning the boom, handle and bucket; $F_{1}, F_{2}, F_{3}$ - forces on the rods of hydraulic cylinders of boom, handle and bucket; $G_{1}, G_{2}, G_{3}, G_{11}$, $G_{21}, G_{31}$ - the forces of gravity of the boom, handle, bucket, hydraulic cylinder boom, handle, bucket; $\alpha_{\mathrm{c}}, \beta, \gamma, \delta, \varphi_{\mathrm{c}}, \varphi_{\mathrm{p}}, \varphi_{\mathrm{\kappa}}$ - are the angles of inclination to the horizontal of the boom, handle, bucket, boom cylinders boom, handle, bucket; $\psi$ - is the angle of inclination of the trajectory of digging to the horizon

We have developed a technique for calculating the forces on the bucket teeth, based on the algorithm for finding an acceptable solution. Before the search, the tangential component of the resistance to digging $P_{01}$ is set, obviously greater than the possible digging effort of the excavator under consideration. According to $P_{01}$, the design forces on the rods of the hydraulic cylinders of the boom Fts, the handle Ftsp and the bucket Ftsk are determined. The calculated forces are compared with the maximum forces of the corresponding hydraulic cylinders. In the event that any of the calculated values Fcc, Fcp or Ffc of the limit values are exceeded, the force $P_{01}$ is reduced, and the calculations are repeated until the maximum forces on the rods of all hydraulic cylinders are greater than or equal to the design forces.

The method of calculating the effort is compiled in the form of a program in an algorithmic language, which includes formulas for calculating coordinates and effort.

The calculated values of the forces on the rods of the hydraulic cylinders of the boom are determined by the condition of equilibrium with respect to the hinge A (see Figure 1)

$$
\sum M_{A}=0 ;
$$




$$
\begin{aligned}
& G_{1}\left(x_{1}-x_{A}\right)+G_{2}\left(x_{2}-x_{A}\right)+G_{3}\left(x_{3}-x_{A}\right)+G_{11}\left(\frac{x_{\mathrm{T}}+x_{\mathrm{E}}}{2}-x_{A}\right)+G_{21}\left(\frac{x_{\mathrm{F}}+x_{\mathrm{P}}}{2}-x_{A}\right)+ \\
& +G_{31}\left(\frac{x_{\mathrm{R}}+x_{\mathrm{D}}}{2}-x_{A}\right)+P_{\mathrm{y}}\left(x_{\mathrm{\kappa}}-x_{A}\right)+P_{\mathrm{x}}\left(y_{\mathrm{\kappa}}-y_{A}\right)-F_{1} \cdot L_{A T} \sin \left(\pi-\alpha_{0}-\varphi_{c}\right)=0,
\end{aligned}
$$

where $P_{x}=-P_{01} \cos \psi-P_{02} \sin \psi-$ projection on the $\mathrm{x}$-axis of the resistance to digging;

$$
P_{y}=-P_{01} \sin \psi+P_{02} \cos \psi-\text { projection on the y-axis of the resistance to digging; }
$$

$x_{1}, x_{2}, x_{3}$ - coordinates along the $\mathrm{x}$-axis of the center of gravity of the boom, stick and bucket;

$x_{\mathrm{A}}, y_{\mathrm{A}}, x_{\mathrm{T}}, x_{\mathrm{E}}, x_{\mathrm{F}}, x_{\mathrm{P}}, x_{\mathrm{R}}, x_{\mathrm{D}}-$ the coordinates of the corresponding hinges;

$x_{\mathrm{K}}, y_{\mathrm{K}}$ - coordinates of the top of the bucket tooth.

$$
\begin{gathered}
F_{1}=\frac{G_{1}\left(x_{1}-x_{A}\right)+}{G_{2}\left(x_{2}-x_{A}\right)+G_{3}\left(x_{3}-x_{A}\right)+G_{11}\left(\frac{x_{\mathrm{T}}+x_{\mathrm{E}}}{2}-x_{A}\right)+G_{21}\left(\frac{x_{\mathrm{F}}+x_{\mathrm{P}}}{2}-x_{A}\right)+} \\
+\frac{G_{31}\left(\frac{x_{\mathrm{R}}+x_{\mathrm{D}}}{2}-x_{A}\right)+P_{\mathrm{y}}\left(x_{\mathrm{K}}-x_{A}\right)+P_{\mathrm{x}}\left(y_{\mathrm{K}}-y_{A}\right)}{L_{A T} \sin \left(\pi-\alpha_{0}-\varphi_{c}\right)} .
\end{gathered}
$$

The forces on the rods of the hydraulic cylinders of the handle are determined by the condition of equilibrium with respect to the hinge $\mathrm{B}$. On the hinge $\mathrm{B}$, in addition to the force in the rod, half of the force of gravity of the handle hydraulic cylinder

$G_{2}\left(x_{2}-x_{B}\right)+G_{3}\left(x_{3}-x_{B}\right)+G_{31}\left(\frac{x_{\mathrm{R}}+x_{\mathrm{D}}}{2}-x_{B}\right)+P_{\mathrm{y}}\left(x_{\mathrm{\kappa}}-x_{B}\right)+P_{\mathrm{x}}\left(y_{\mathrm{K}}-y_{B}\right)+0,5 G_{21}\left(x_{P}-x_{B}\right)-$

$-F_{2} \cdot L_{B P} \sin \angle F P B=0$

$F_{2}=\frac{G_{2}\left(x_{2}-x_{B}\right)+G_{3}\left(x_{3}-x_{B}\right)+G_{31}\left(\frac{x_{\mathrm{R}}+x_{\mathrm{D}}}{2}-x_{B}\right)+P_{\mathrm{y}}\left(x_{\mathrm{\kappa}}-x_{B}\right)+P_{\mathrm{x}}\left(y_{\mathrm{\kappa}}-y_{B}\right)+0,5 G_{21}\left(x_{P}-x_{B}\right)}{L_{B P} \sin \angle F P B}$

The forces on the rods of the bucket hydraulic cylinders are determined by the condition of equilibrium with respect to the hinge $C$. On the hinge $C$, in addition to the force in the rod, half the gravity force of the bucket hydraulic cylinder

$$
\begin{gathered}
G_{3}\left(x_{3}-x_{c}\right)+P_{\mathrm{y}}\left(x_{\mathrm{\kappa}}-x_{C}\right)+P_{\mathrm{x}}\left(y_{\mathrm{\kappa}}-y_{C}\right)-0,5 G_{31}\left(x_{D}-x_{C}\right)-F_{3} \cdot L_{C D} \sin \angle R D C=0 . \\
F_{3}=\frac{G_{3}\left(x_{3}-x_{C}\right)+P_{\mathrm{y}}\left(x_{\mathrm{\kappa}}-x_{C}\right)+P_{\mathrm{x}}\left(y_{\mathrm{\kappa}}-y_{C}\right)-0,5 G_{31}\left(x_{D}-x_{C}\right)}{L_{C D} \sin \angle R D C},
\end{gathered}
$$

where $L_{A T}, L_{B P}, L_{C D}$ - distance between corresponding hinges.

Reactions in the hinge "boom heel - platform" (point A)

$$
\begin{gathered}
R_{A x}=-F_{1} \cos \alpha_{c}-P_{x} \\
R_{A y}=-F_{1} \sin \alpha_{c}-P_{y}+G_{3}+G_{2}+G_{1}+G_{31}+G_{21}+0,5 G_{11} .
\end{gathered}
$$

Reactions in the hinge "boom - handle" (point B) 


$$
\begin{gathered}
R_{B x}=-F_{2} \cos \varphi_{p}-P_{x} \\
R_{B y}=-F_{2} \sin \varphi_{p}-P_{y}+G_{3}+G_{2}+G_{31}+0,5 G_{21} .
\end{gathered}
$$

Reactions in the hinge "handle-bucket" (point C)

$$
\begin{gathered}
R_{C x}=-F_{3} \cos \varphi_{\kappa}-P_{x} \\
R_{C y}=-F_{3} \sin \varphi_{\kappa}-P_{y}+G_{3}+0,5 G_{31}
\end{gathered}
$$

The algorithm for calculating the boundaries of the working area and forces at points inside the zone is based on alternating changes in the permissible limits of the distances between the hinges $T E, F P, R D$ (extensions of the rods of hydraulic cylinders), in calculating the coordinates of points and forces for each combination of distances. When determining the boundaries of the working area, the digging process should be considered, if in some area the digging process is impossible - the forces on the bucket teeth do not provide separation of the chips, this zone should be excluded from the area determined by the geometric dimensions of the working equipment.

For the subsequent use in stress calculations, the maximum values of the forces by which the elements are checked for strength are determined.

For calculating the longevity, it is possible to determine the load graphs for individual nodes.

The second option does not require the creation of equations for calculating the forces between the elements, but at the same time the computational model using finite elements for the Strucrure 3D module becomes more complicated.

The boom, hilt and bucket are made up of plate elements, and to ensure the possibility of angular movements (hinges in a real machine), rod elements with hinges at the ends are used. Hydraulic cylinders are also realized with rods with supports and hinges. The model for the excavator with the working equipment is the back shovel shown in Figure. 2, and one of the variants of the calculation in the form of a stress map is shown in Figure 3.

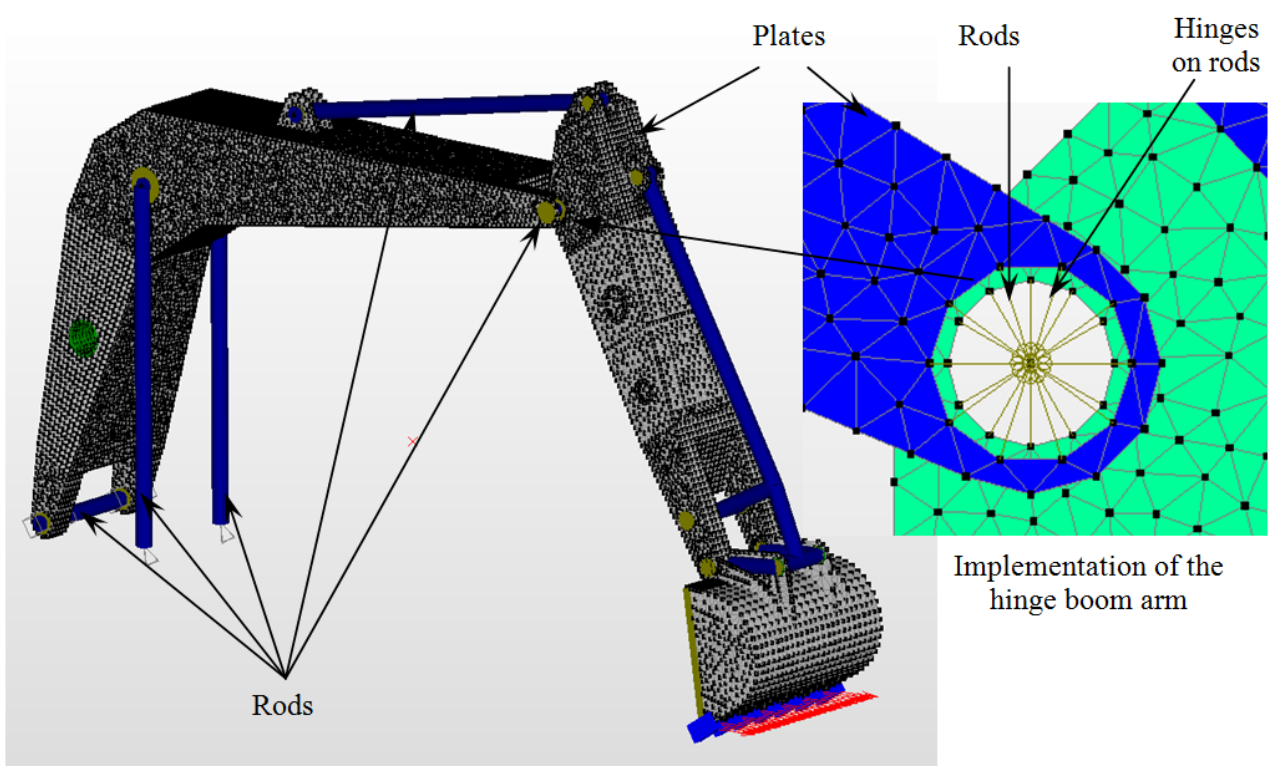

Fig. 2. Plate-rod model of working equipment. 
Efforts on the rods of hydraulic cylinders are determined by efforts on the bucket teeth, approved by the technical design assignment. The Structure module has the function of rotating the entire structure or its individual parts. This allows you to perform calculations at several points in the work area.

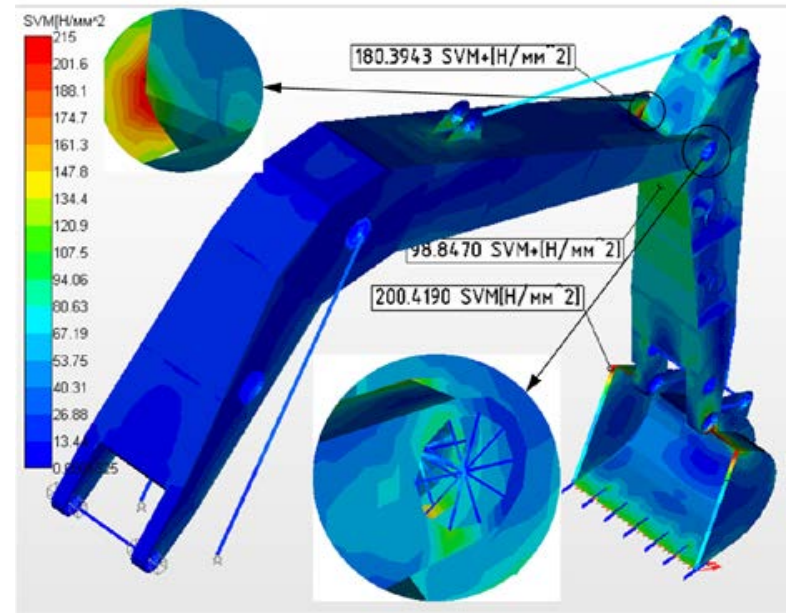

Fig. 3. Results of stress analysis

\section{Conclusions}

1. The developed mathematical model and computer program allow you to determine the forces on the rods of hydraulic cylinders and in the hinges, as well as to specify the working area of the excavator.

2. The technique of using the plate-rod model of the working equipment for determining the forces on the rods of the hydraulic cylinders and the stresses in the elements of the boom, arm and bucket on the digging force.

\section{References}

1. R.Yu. Poderni, P. Boules, Comparative analysis of hydraulic and mechanical excavators with a straight shovel, Mining magazine, № 1, pp. 55-61 (2015).

2. P.A. Pobegailo, Powerful single-bucket hydraulic excavators: Selection of basic geometric parameters of working equipment in the early stages of design (Moscow: LENAND, 296 p., 2014).

3. Yu.A. Lagunova, A.P. Komissarov, V.S. Shestakov, Design of mining excavators (Moscow: Innovative Mechanical Engineering, 228 p., 2017).

4. R.Yu. Poderni, P. Boules, Efficiency of the use of powerful hydraulic excavators is the result of increasing their reliability, Mining magazine, No. 1 (119), p. 46 (2015).

5. A.A. Khoreshok, E.Yu. Pudov, Designing of a perspective design design of a bucket of a hydraulic excavator of the scheme "Reverse shovel", Mining equipment and electromechanics, No. 8, p. 37-44 (2014).

6. I.Yu. Ivanov, A.P. Komissarov, I.V. Teliman, O.A. Lukashuk, Analysis of leverhydraulic mechanisms of working equipment of hydraulic excavators, Technological equipment for mining and oil and gas industry, Proceedings of the XV International 
Scientific and Technical Conference, Ekaterinburg: Ural State University, pp. 51-54 (2017).

7. V.Y. Krikun, V.G. Manasyan, Calculation of the main parameters of hydraulic excavators with working equipment backhoe, Proceedings: Publishing House: ASV, 104 p. (2001).

8. P.A. Zykov, A technique for the optimal choice of a single-bucket hydraulic excavator model for the given mining-geological and technical conditions, Mining equipment and electromechanics, No. 1, pp. 37-42 (2014).

9. P.Yu. Babenkov, V.S. Shestakov, Modeling of the working process of a hydraulic excavator, Mining equipment and electromechanics, No. 1, pp. 10-14 (2018).

10. V.S. Shestakov, S.A. Khoroshavin, Optimization of the working equipment of hydraulic excavators, Mining equipment and electromechanics, № 5, pp. 50-53 (2011).

11. S.I. Sushkov, V.N. Makeev, D.D. Pleshkov, Analysis of design features of lifting mechanisms of hydraulic excavators, Construction and road machinery, № 6, pp. 13-15 (2012).

12. G.N. Karasev, V.P. Pavlov, Road construction machinery. System design, modeling, optimization, Krasnoyarsk: SFU, 241 p. (2011).

13. P.A. Pobegailo, A mathematical model for determining the loading of a single-bucket hydraulic excavator for back digging, Interstroymech, p. 179-181 (2002).

14. G.T. Gruening, G. Kunze, A Katterfeld, Simulating the working process construction machines, In: Bulk Solids Europe 2010. Glasgow, Scotland, 10 p. (2010).

15. S, Li Y. Frimpong, Virtual Prototype Simulation of Hydraulic Shovel Kinematics for Spatial Characterization in Surface Mining Operation, International Journal of Surface Mining, Reclamation and Environment, Vol. 19, № 4, pp. 238 - 250 (2005). 